\title{
Patients' Satisfaction in Modified Radical Mastoidectomy Done Under Local Anesthesia for Squamous Type of Chronic Otitis Media
}

\author{
Ramesh Parajuli ${ }^{1 *}$, Rakesh Prasad Shrivastav ${ }^{2}$ and Hari Bhattarai ${ }^{2}$ \\ ${ }^{1}$ Department of Otorhinolaryngology, Chitwan Medical College Teaching Hospital, Nepal \\ ${ }^{2}$ Department of Otorhinolaryngology, Tribhuvan University Teaching Hospital, Institute of Medicine, Kathmandu, Nepal
}

Submission: February 01, 2017; Published: February 09, 2017

*Corresponding author: Ramesh Parajuli, Department of Otorhinolaryngology, Chitwan Medical College Teaching Hospital, P.O.Box:42, Chitwan, Nepal, Tel: +977-56-532933; Fax: +977-56-532937; Email: drrameshparajuli@gmail.com; sukhaura@gmail.com; rakesh2019@gmail.com

Abstract

Objective: The objective of this study was to assess patients' satisfaction in modified radical mastoidectomy done under local anesthesia.

Materials and methods: It was an exploratory study carried out in 30 adults. Questionnaire having scoring system that ranged from ' 0 ' to ' 4 ' $(0=$ very satisfied and $4=$ very dissatisfied $)$ was used to measure satisfaction. Patients' discomforts during surgery were assessed using the same scoring system that ranged from ' 0 ' to ' 4 ' $(0=$ no problem and $4=$ severe problem $)$.

Results: Earache and noise during surgery were the two most unpleasant discomforts with a mean score of 1.83 and 1.43 respectively, which lies between 'somewhat of a problem' to 'moderate problem' (score between ' 1 ' and ' 2 '). In spite of these discomforts (earache, noise, anxiety, body ache, nausea, palpitation); 15 patients (50\%) were satisfied and 7 patients $(23.3 \%)$ were very satisfied. Moreover, 20 patients (86\%) said that they would have a similar operation under local anaesthesia in the future if needed.

Conclusion: Modified radical mastoidectomy can be performed under local anaesthesia satisfactorily in a selected group of patients in spite of the fact that it is an operation of relatively longer duration with a long drilling time.

Keywords: Modified radical mastoidectomy; Local anesthesia; Patients' satisfaction

Abbreviations: WHO: World Health Organization; COM: Chronic Otitis Media; MRM: Modified Radical Mastoidectomy; LA: Local Anesthesia; GA: General Anaesthesia

\section{Introduction}

Chronic otitis media (COM) is a global disease, seen in all the continents of the world having but it is most prevalent in developing countries [1]. It is a chronic inflammatory disease of the middle ear cleft, which presents with recurrent ear discharge, partial or total loss of the tympanic membrane and hearing impairment with or without ossicular involvement. The World Health Organization (WHO) estimates that 360 million people worldwide suffer from disabling deafness [2]. COM is still one of the commonest ear diseases in many of the developing countries. The prevalence of COM in Nepal is 7.2\% [3]. However the prevalence of squamous type of COM in Nepal is 3.5\% [4].

$\mathrm{COM}$ is the most common cause of mild to moderate hearing impairment in children and young adults in developing countries [5]. Nepal is a developing country, where hearing impairment is the single largest disability. The etiology and pathogenesis of COM are multifactorial and include genetic, infections, allergy, environmental, social and racial factors and Eustachian tube dysfunction [6]. Poor living conditions, overcrowding, poor hygiene and nutrition have been suggested as the basis for the widespread prevalence of COM in developing countries [7]. In addition ignorance, poverty and traditional beliefs are the major risk factors for not attending hospital in rural parts of Nepal [8].

The management of squamous type of COM is mainly surgical. Modified radical mastoidectomy (MRM) is the surgery of choice in most patients. The use of local anesthesia (LA) for middle ear surgery has a long history. Nowadays most of the Otolaryngologists worldwide do not prefer it because of concerns that the patient may not be able to tolerate discomfort 
during the operation and because of which the surgeon may not be able to work comfortably. In a developing country like Nepal, cost of surgery along with the cost of anaesthetic equipment and availability of an anaesthesiologist is a major concern. General anaesthesia (GA) is not only costly but also needs an anaesthesiologist and hence a special set up is required. Because of lack of such special set ups and anaesthesiologists in Nepal, there is usually a long waiting list for the surgery under GA. In this study we aimed to carry out a survey to assess patients' satisfaction in MRM done under LA for active stage of squamous type of COM.

\section{Materials and methods}

An exploratory study was carried out at the department at Tribhuvan University Teaching Hospital, Kathmandu. The study period was from October 2009 to March 2011. The inclusion criteria set for the study being, the patient of both gender above the age of 13 years having active stage of COM squamous type who give consent for MRM under LA. The exclusion criteria were; patients with complications of COM, patients undergoing revision MRM, patients with cardiac diseases such as ischaemic heart disease and hypertension, patient undergoing MRM under LA who needs to be converted into GA before completion of the procedure. Informed consent was taken from all patients preoperatively after explaining the procedure. Ethical approval was taken from Institution Review Board. Patients were counseled for the type of anaesthesia they would prefer either LA or GA and scheduled for surgery as per their choice. Patients were advised for pure tone audiometry and x-ray mastoid lateral oblique and Towne's views. Routine investigations performed in these patients were complete blood count, Chest X-ray, Electrocardiogram, serum electrolytes, random blood sugar, serology and urine routine examinations. Patients were admitted one day prior to surgery in the ENT ward. Prophylactic antibiotic either amoxicillin $500 \mathrm{mg}$ or ciprofloxacin $500 \mathrm{mg}$ was started orally one day prior to surgery.

\section{Local anaesthesia technique}

Vital signs were taken and then intravenous line was Results opened which was followed by deep intramuscular injection of Meperidine $50 \mathrm{mg}$ mixed with injection promethazine $25 \mathrm{mg}$, about 30 to 45 minutes before surgery. Local anesthetic injection consisting of $2 \%$ Lidocaine with adrenaline 1: 46,900 (prepared by adding $0.5 \mathrm{ml}$ of $1: 000$ adrenaline in a vial containing $30 \mathrm{ml}$ of 2\% Lidocaine (Lignocaine) with 1: 200000 adrenaline) was infiltrated in the post auricular region in a ' $\mathrm{V}$ ' pattern and deep infiltration upto the periosteum in the 4 quadrants of the external auditory canal at the junction of bony and cartilaginous was given. Average of $14 \mathrm{ml}$ of this solution was injected. Topical lignocaine $4 \%$ solution was also used if required during surgery especially when working in the middle ear.

\section{Surgical technique}

Now regarding the surgery, that is, MRM the skin incision used to access the mastoid bone was either endaural or postaural. The surgical technique used for mastoidectomy was either 'in to out' that is the drilling of bone started from attic to mastoid antrum via the aditus; or 'out to in' where the drilling of bone started from mastoid antrum to attic via aditus. Temporalis fascia was harvested as graft material. The wound was closed in three layers. Periosteum and soft tissue were closed with 'Vicryl' 3.0 and skin was closed with 'Ethilon' 3.0.

\section{Outcome measure}

Six to eight hours after operation, patients were asked to fill the questionnaire regarding their intra-operative experience. To measure patients' discomfort during surgery we analyzed 8 self-administered questionnaires to identify particular intraoperative and early post-operative symptoms: anxiety, earache, palpitation, noise, nausea, vomiting, body ache and neck pain. Patients were also asked to report their most unpleasant symptom. To measure the patients' discomfort the ' 0 ' to ' 4 ' scoring system used by Sarmento et al. [9] and Caner et al. [10] and for patient's satisfaction the 5 point Likert Scale was used in this study. Statistical analysis was done using the SPSS Software (16.0). Mean scores of patients' discomforts were calculated. Measurement of patients' satisfaction was done.

Table 1: Patients' discomfort score $(n=30)$.

\begin{tabular}{|c|c|c|c|c|c|c|c|c|}
\hline & & \multicolumn{3}{|l|}{ Score (0 to 4) along with number of patients } & \multirow{2}{*}{ Total patients } & \multirow{2}{*}{ Mean score } \\
\cline { 2 - 7 } & Parameter & $\mathbf{0}$ & $\mathbf{1}$ & $\mathbf{2}$ & $\mathbf{3}$ & $\mathbf{4}$ & $\mathbf{0}$ to 4 \\
\hline 1 & Discomfort due to anxiety & 20 & 5 & 2 & 2 & 1 & 30 & 0.63 \\
\hline 2 & Discomfort due to noise & 11 & 4 & 8 & 5 & 2 & 30 & 1.43 \\
\hline 3 & Discomfort from earache due to Local anesthetic & 17 & 9 & 3 & 1 & 0 & 30 & 0.60 \\
\hline 4 & infiltration & 4 & 5 & 14 & 6 & 1 & 30 & 1.83 \\
\hline 5 & Discomfort from earache during surgery & 18 & 3 & 7 & 2 & 0 & 30 & 0.76 \\
\hline 6 & Discomfort due to intra-operative nausea and vomiting & 23 & 4 & 3 & 0 & 0 & 30 & 0.33 \\
\hline 7 & Discomfort due to post-operative nausea and vomiting & 24 & 5 & 1 & 0 & 0 & 30 & 0.23 \\
\hline 8 & Discomfort due to palpitation & 23 & 4 & 1 & 1 & 1 & 30 & 0.43 \\
\hline
\end{tabular}




\section{Global Journal of Otolaryngology}

Table 2: Patients' most unpleasant discomfort $(n=30)$.

\begin{tabular}{|c|c|c|}
\hline & Most unpleasant symptom & $\begin{array}{c}\text { Number of patients } \\
\text { (Percentage) }\end{array}$ \\
\hline 1 & Earache & $21(70 \%)$ \\
\hline 2 & Noise & $5(16.6 \%)$ \\
\hline 3 & Body ache and neck pain & $2(6.6 \%)$ \\
\hline 4 & Anxiety & $1(3.3 \%)$ \\
\hline 5 & Palpitation & $1(3.3 \%)$ \\
\hline
\end{tabular}

There were a total of 30 patients; 17 were males and 13 were females. The age of the patients ranged from 16 years to 63 years with the mean age being 26.6 years. Most of the patients belonged to age group 13 to 20 years (12 patients; $40 \%$ ). Assessment of patients' discomfort during surgery using ' 0 ' to ' 4 ' point scoring method is shown in (Table 1). Patients were asked to report the most unpleasant discomfort they experienced during surgery; which is shown in (Table 2). Patients' overall satisfaction about the surgery under LA is shown in (Table 3). Finally, the patients were also asked about their willingness for LA for similar operation in the future. Of the 30 patients 26 patients (86\%) were willing to have a similar operation under LA in the future if needed, while 4 patients (14\%) refused to have LA for similar operation if required again. No intra-operative or early postoperative complications were observed.

Table 3: Patients' overall satisfaction $(n=30)$.

\begin{tabular}{|c|c|c|}
\hline & Grading of satisfaction & $\begin{array}{c}\text { Number of patients } \\
\text { (Percentage) }\end{array}$ \\
\hline 1 & Very satisfied & $7(23.3 \%)$ \\
\hline 2 & Satisfied & $15(50 \%)$ \\
\hline 3 & $\begin{array}{c}\text { Neither satisfied nor } \\
\text { dissatisfied }\end{array}$ & $5(16.6 \%)$ \\
\hline 4 & Dissatisfied & $2(6.6 \%)$ \\
\hline 5 & Very dissatisfied & $1(3.3 \%)$ \\
\hline
\end{tabular}

\section{Discussion}

COM is seen in all the continents of the world. It is most prevalent in developing countries like Nepal. It is of 2 types, that is, mucosal and squamous. The squamous type is also known as unsafe type as it can lead to various complications; the management of which is mainly surgical.MRM is the surgery of choice in these patients that can be performed both under local and general anaesthesia. GA and LA have their own advantages and disadvantages. The advantages of LA include less bleeding during surgery, early mobilization of patient, cost-effectiveness and the ability to test hearing restoration during surgery [9-13]. It also helps to release the anesthetic capacity of the hospital for other major procedures [14]. LA can also be used by nonanaesthesiologists which are very useful in country like ours where there are only limited numbers of anaesthesiologists who are primarily available in major cities. LA is useful to reduce the waiting list for the middle ear surgery under GA. Despite these advantages of LA most middle ear surgery is still performed under GA because of concerns that the patient may not be able to tolerate discomfort during the operation and due to which the surgeon may not be able to work comfortably.

The scoring system used by Sarmento et al. [9] and Caner et al. [10] was adopted to score the severity of discomfort due to various symptoms during surgery. To measure the overall satisfaction the 5-point Likert response set, which is the frequently used scale in survey design; was used. Inclusion criteria of age was kept above 13 years because all paediatric ENT related problems of children up to 12 years is dealt by Paediatric Unit of the ENT department. Moreover, for children 12 years and younger it would be very difficult if not impossible to tolerate or go through the entire surgery under LA. In this study the age of the patients ranged from 16 years to 63 years with a mean age of 26.6 years. Sarmento et al. [9] included only patients above 18 years of age in their study with age range between 18 to 58 years and the mean age of 34.2 years. In a study done by Caner et al. [10] the mean age of the patient was 27.8 years, with age range of 13 to 55 years. In a study by Lancer JM [11] age of the patients ranged between 19 to 64 years old (mean 46 years). This study is only one of its kinds where the age of the patient was less than 18 years. Most other studies have taken patients 18 years of age and above.

In this study a solution of lignocaine $2 \%$ containing $1: 46,900$ adrenaline was used for local anaesthetic infiltration. The concentration of lignocaine and adrenaline used for middle ear surgery under LA varies from study to study. No study to date has addressed the issue of optimal concentration of adrenaline for Otologic surgery [12]. In several studies either $1 \%$ or $2 \%$ of lignocaine with adrenaline concentration varying from $1: 200,000$ to $1: 15,000$ was used $[9,10,15]$. There was no significant difference in the blood flow when either 1:50,000, $1: 100,000$ or $1: 200,000$ adrenaline containing lignocaine solution was used [13] Singh S [14] used bupivacaine 0.5\% with adrenaline 1:200,000 for in his study of tympanomastoidectomy. Bupivacaine has the advantage that it is more potent than lignocaine and its duration of action lasts longer when combined with adrenaline [14]. However, bupivacaine has increased risk of cardiac toxicity and the neurotoxicity.

Therefore lignocaine was used as a local anesthetic agent in this study. Although in this study local anaesthetic solution containing a concentrated adrenaline solution was used, there were no systemic toxic reactions. There are many studies in literature using propofol, midazolam, diazepam and dexmedetomidine as sedative agent for conscious sedation during middle ear surgery under LA $[16,17]$. Pethidine has a number of favorable properties when used for conscious sedation which is well accepted by the patients and the surgeons. Conscious sedation is desirable during middle ear surgery to allow the surgeon to communicate with the patient throughout the operation and to test the patient's hearing after any 
hearing restoration procedure [16]. Rescue medications were made available during the operation.

In our study the mean value of earache due to LA infiltration was 0.60 . However, the mean value of earache during surgery was the highest discomfort score among all other discomforts with a mean score of 1.83 . The mean score was between 'somewhat of a problem' to 'moderate problem' (score between ' 1 ' and ' 2 '). In a study by Sarmento et al. [9] mean value of pain during 51 surgeries was 0.83 . In a study by Caner et al. [10] the mean value of earache during surgery was 0.94 . Out of 23 patients who underwent mastoidectomy in a study done by Yung MW [15], 1 patient (4.3\%) complained earache as the most intense discomfort. In various other studies earache during middle ear surgery was not found to be a significant discomfort. However, the results of this study showed that the most intense discomfort to the patients was earache during surgery.

This could be because most of the patients in this study had granulation tissue along with cholesteatoma within the tympanic cavity where there was active inflammation, which might have decreased the efficacy of LA and caused increased pain sensation. In various studies reviewed, most of the surgeries were either myringoplasty or stapedotomy where very little manipulation is done in the tympanic cavity and also because the middle ear mucosa is not inflamed the action of LA is better.

The mean value of discomfort due to noise was 1.43, which was the second highest mean of the various discomforts experienced by the patients after earache. In a study by Caner et al. [10] the mean value of discomfort due to noise during surgery was 0.96 . In a study by Sarmento et al. [9] mean value of the discomfort due to noise during surgery had the lowest mean of 0.70 , among all the discomforts experienced by the patient. The high mean value of noise in this study might have been caused by the prolonged use of drill and suction which was used in all of the patients, who underwent MRM. Majority of operations in the studies by and Sarmento et al. [9] and Caner et al. [10] were myringoplasty, tympanoplasty and stapes surgery where very little suction and drill work is required if at all.

Similarly, discomfort due to body ache and neck pain was found to be a major issue in studies by Yung MW [15] and Caner et al. [10]. In the study of Sarmento et al. [9] discomfort due to body ache and neck pain had the highest mean value of 1.51 among all the discomforts experienced by the patients. The mean value of body ache and neck pain in this study was 0.76 . The low mean score value of discomfort due to body ache and neck pain in this study might be due to proper pre-operative counseling and the adequate sedation during surgery.

The mean value of palpitation in this study was 0.43 , which is in between 'no problem' to 'somewhat of a problem' (score between ' 0 ' and ' 1 ').In this study anxiety experienced by the patients had a mean score of 0.63 which was between 'no discomfort' and 'mild discomfort' (score between ' 0 ' and ' 1 ').
Sarmento et al. [9] had similar results, that is mean score of 0.89 which means that the discomfort due to anxiety during surgery was between 'no discomfort' and 'mild discomfort' (score between ' 0 ' and ' 1 '). However, in a study by Caner et al. [10] the anxiety means score was 1.11. Similarly in the study by Yung MW [15] discomfort due to anxiety was the most intense discomfort second only after the discomfort due to noise. The low mean value in our study might be because of adequate sedation and good preoperative counseling which decreased the level of anxiety among the patients.

The reported incidence of post-operative nausea and vomiting after middle ear surgery is 62 to $82 \%$ when no prophylactic antiemetic was given $[18,19]$. In this study the discomfort from intra-operative and post-operative nausea and vomiting had the lowest mean score of 0.33 and 0.23 respectively. None of the patients in this study had vomiting in the intra-operative and post-operative period. In this study earache and noise (from drilling and suctioning) during mastoid surgery were the most unpleasant discomforts experienced by the patients. Earache was experienced by 21 out of the 30 patients $(70 \%)$ while discomfort due to intra-operative noise was experienced by 5 out of 30 patients $(16.6 \%)$.

Patients' choice in favor of LA for a similar procedure if needed in the future in this study in spite of these discomforts may be due to various reasons. Early mobilization of the patient in a short time and the chance of being able to communicate with the surgeon during the procedure are probably the most common reasons. Most of the patients in this study were from rural areas and are illiterates and were also uneducated and, therefore, highly anxious. Uneducated patients in a developing country like Nepal fear that they may not wake up again after GA and this may be another reason for preferring LA.

With correct selection of patients and proper pre-operative counseling of the procedure, various risks such as sudden body movement could be avoided or minimized. In order not to bring the middle ear surgery under LA into disrepute, patients should be assessed meticulously pre-operatively by an experienced surgeon so that operation under LA is not performed in unsuitable patients. Moreover as the patient is selected for LA, he or she should be properly counseled and given adequate pre-operative sedation. Generally speaking, most patients like to be guided by the surgeon as to the choice of anaesthesia and surgical procedure to be adopted. Therefore, it is imperative that the surgeon should have the experience of performing middle ear surgeries under both forms of anaesthesia and the surgeon should be able to offer the patient an informed choice. This study demonstrated that LA was associated with the minor discomforts to the most of the patients and was probably responsible for good patients' satisfaction.

The limitations of this study were: This study had a small sample size that may not have yielded a result that could have wider application in general population. Several factors can 
influence the results of patient satisfaction questionnaires. We tried to eliminate selection bias by including all the patients who undergone MRM under local anaesthesia. Similarly, response bias can also influence the results of patient satisfaction questionnaires. All of our patients in this study responded to the questionnaire in early post-operative period. Similarly the racial demographics of the local population can have impact on the results of satisfaction as the pain threshold may differ in people of different ethnicity and regions but this was not a major issue in our study as it included people from different parts of the country. Because it was carried out it the capital city where many people from different parts of the country come for surgery. It would be more useful to compare the patient satisfaction in MRM done under LA and GA, but this was not practical as the patient is amnesic for the intra-operative event if the surgery is performed under general anaesthesia.

\section{Conclusion}

Earache and the noise during surgery were the two most common discomforts in patients undergoing MRM under LA. MRM under LA was well tolerated by most of the patients in spite of the fact that: It is an operation of relatively long duration with exposure of the patient to prolonged and high level of noise as a result of long duration of drilling and use of suction. MRM under LA is in fact a boon because it is economically feasible in developing countries.

\section{References}

1. Wakode PT, Joshi SV, Gawarle SH (2006) Chronic suppurative otitis media in school going children. Indian journal of Otolaryngology and Head and Neck Surgery 58(2): 152-155.

2. Deafness and hearing impairment. In:http:/ www.who.int/ mediacentre/ factsheets /fs $300 / \mathrm{en}$

3. Little P, Brigges A, Guragain R, Friedman D, Prasad R, et al. (1993) Hearing impairment and ear pathologies in Nepal. J Laryngol Otol 107(5): 395-400.

4. Browing GG, Gatehouse S (1992) The prevalence of middle ear disease in the adult British population. Clin Otolaryngol 17(4): 317-321.

5. Biswas AC, Joarder AH, Siddiquee BH (2005) Prevalence of CSOM among rural school going children. Mymensingh Med J 14(2): 152-155.
6. Maharjan M, Bhandari S, Singh I, Mishra SC (2006) Prevalence of otitis media in school going children in eastern Nepal. Kath Univ Med J 16(4): 479-482.

7. Mills RP (1997) Management of chronic suppurative otitis media. In: Scott Brown's otolaryngology, Vol 3, ( $\left.6^{\text {th }} \mathrm{edn}\right)$, Reed Educational and Professional Publishing ltd, London, UK.

8. Adhikari P (2009) Prevalence of chronic suppurative otitis media in Nepalese children: Experience of free health camps. The internet Journal of Otorhinolaryngology 10(2): 1-5.

9. Sarmento KM A, Tomita S (2009) Retroauricular tympanoplasty and tympanomastoidectomy under local anaesthesia and sedation. Acta Oto Laryngologica 129(7): 726-728.

10. Gül Caner, Levent Olgun, Gürol Gültekin, Levent Aydar (2005) Local anesthesia for middle ear surgery. Otolaryngol Head Neck Surg 133(2): 295-297.

11. Lancer JM, Fisch U (1988) Local anesthesia for middle ear surgery. Clin Otolaryngol 13(5): 367-374.

12. Gessler EM, Hart AK, Dunlevy TM, Greinwald JH Jr (2001) Optimal concentration of epinephrine for vasoconstrictor in ear surgery. Laryngoscope 111(10): 1687-1690.

13. Sundar Singh (1995) Study of tympanomastoidectomy under local anaesthesia using bupivacaine. Indian Journal of Otolaryngology and Head and Neck Surgery 2(2): 144-146.

14. American Society of Anesthesiologists Task Force on Sedation and Analgesia by Non-Anesthesiologists (2002) Practice guidelines for sedation and analgesia by non-anesthesiologists. Anesthesiology 96(4): 1004-1017.

15. Yung MW (1996) Local anaesthesia in middle ear surgery: Survey of patients and surgeons. Clin Otolaryngol Allied Sci 21(5): 404-408.

16. Janez Benedik, Aleksander Manohin (2008) Sedation for middle ear surgery: Prospective clinical trial comparing propofol and midazolam. Central European Journal of Medicine 3(4): 487-493.

17. Vega Sepulveda RA (2005) Dexmedetomidine: A new alpha-2 agonist anaesthetic agent in fusion for sedation in middle ear surgery with awake patient. Anaesthesiology 487-493.

18. Honkavaara P, Saarinvaara L, Klemola UM (1994) Prevention of nausea and vomiting with transdermal hyocine in adults after middle ear surgery during general anesthesia. British Journal of Anaesthesia 73: 763-766.

19. Reinhart DJ, Klein KW, Schroff E (1994) Transdermal scopolamine for the reduction of postoperative nausea in outpatient ear surgery: a double-blind, randomized study. Anesth Analg 79(2): 281-284.

\section{Your next submission with Juniper Publishers will reach you the below assets}

- Quality Editorial service

- Swift Peer Review

- Reprints availability

- E-prints Service

- Manuscript Podcast for convenient understanding

- Global attainment for your research

- Manuscript accessibility in different formats

( Pdf, E-pub, Full Text, Audio)

- Unceasing customer service

Track the below URL for one-step submission https://juniperpublishers.com/online-submission.php 